\begin{tabular}{|l|l|}
\hline & \\
&
\end{tabular}

SEÇÃO: ARTIGOS E ENSAIOS

\title{
Demandas dos povos da floresta e a oferta da Política de Assistência Social no contexto amazônico brasileiro
}

\author{
Demands of the peoples of the forest and the provision of the Social Assistance Policy in \\ the Brazilian Amazon context
}

\author{
Dayana Cury Rolim ${ }^{1}$ \\ orcid.org/0000-0001-7485-8956 \\ dayanarolim@ufam.edu.br
}

Recebido em: 21 fev. 2020 Aprovado em: : 4 out. 2021 Publicado em: 30 dez. 2021.
Resumo: O artigo objetivou analisar as demandas das famílias usuárias dos Centros de Referência da Assistência Social (CRAS) e a oferta da Política de Assistência Social no municipio de Parintins, no estado do Amazonas. O Brasil possui diferentes territórios com demandas especificas que devem ser respeitadas, considerando as desigualdades socioterritoriais existentes. Estas reflexões são fruto de uma das discussões da tese de doutorado defendida em 2017. tendo como procedimento metodológico a pesquisa de campo com abordagem quantiqualitativa a partir de entrevistas a 40 famílias da área urbana e rural. Conclui-se que a análise da demanda potencial ainda é um grande desafio para a assistência social, adequá-la à oferta dos serviços e benefícios socioassistenciais, à luz da perspectiva do território, significa conduzir as necessidades de proteção ao diálogo com as provisões do Sistema Único de Assistência Social (Suas) de acordo com a realidade local.

Palavras-chave: Demanda. Oferta. Política de assistência social. Contexto amazônico

Abstract: The article aimed to analyze the demands of families that use Social Assistance Reference Centers (CRAS) and the offer of the Social Assistance Policy in the municipality of Parintins, in the state of Amazonas. Brazil has different territories with specific demands that must be respected, considering the existing socio-territorial inequalities. These reflections are the result of one of the discussions of the doctoral thesis defended in 2017, having as methodological procedure the field research with a quanti-qualitative approach based on interviews with 40 families from urban and rural areas. It is concluded that the analysis of potential demand is still a great challenge for social assistance, adapting it to the offer of social assistance services and benefits, in light of the perspective of the territory, means bringing the protection needs into dialogue with the provisions of the System Social Assistance Service (SUAS) according to the local reality.

Keywords: Demand. Offer. Social assistance policy. Amazonian context.

\section{Introdução}

O Brasil apresenta uma enorme extensão territorial dividida em regiões, as quais revelam particularidades que devem ser respeitadas na implementação de políticas públicas e oferta de serviços. É necessário conhecer as diferenças e desigualdades que distinguem os territórios, para enfrentar os desafios e ofertar serviços compativeis às realidades locais. 
A territorialização do Suas, com a implantação de serviços e equipamentos estatais nos territórios mais vulneráveis, tem como missão viabilizar o acesso da população em situação de pobreza, vulnerabilidade social e econômica a um conjunto de serviços, programas e projetos, além de outras políticas públicas. Porém, precisa avançar na visibilidade dos povos tradicionais e outras populações no sentido de garantir direitos de acordo com as suas especificidades culturais.

AAmazônia brasileira possui uma área geográfica extensa e ainda pouco povoada, apesar de nas últimas três décadas ter passado por um rápido e intenso processo de povoamento e de urbanização.

Compreende-se que devido ao imenso território amazônico muitos municipios encontram desafios como, por exemplo, as distâncias intermunicipais, as vias de deslocamentos, em muitos casos, apenas fluviais, o que implica, sobretudo na questão espaço/tempo com longas viagens até chegar ao destino final.

As implicações de deslocamento, devido ao vasto território, deixam muitas familias ainda invisiveis às políticas públicas. $O$ século $X X I$ nos mostra o quanto se deve avançar no quesito cidadania, notadamente quando se constata adultos e crianças que não têm a sua documentação de cidadão e deixam de exercer os seus direitos.

Cada município amazônico possui especificidades territoriais em seu modo de vida e na sua relação com a natureza diante da diversidade dos ecossistemas regionais, caracterizada em muitas localidades pelas terras de várzea, que sofrem com as enchentes dos rios e as terras firmes que não são impactadas pelas inundações.

Deste modo, a discussão apresentada neste artigo faz o seguinte questionamento: os serviços e programas ofertados pela Política de Assistência Social estão atendendo às demandas da população amazônida, de acordo com as suas peculiaridades regionais, em particular no município de Parintins, no estado do Amazonas?

Este artigo apresenta-se como parte de uma discussão levantada na tese de doutorado, defendida em dezembro de 2017. Metodologicamente, realizou-se entrevistas com 40 familias usuárias do
Sistema Único de Assistência Social, cadastradas no Centro de referência da Assistência Social e beneficiárias do Programa Bolsa Familia, do municipio de Parintins, locus da pesquisa, situado na região do Baixo Amazonas, no estado do Amazonas, próximo à divisa com o estado do Pará. Parintins tornou-se um dos pontos turísticos mais importantes da Amazônia devido ao Festival Folclórico, onde ocorre a apresentação dos bois Bumbás Garantido e Caprichoso. O acesso à cidade de Parintins se dá através dos transportes fluvial e aéreo.

O Suas é uma realidade em construção e que tem mudado a vida de muitos brasileiros, principalmente diante do cenário de crise e desmonte de direitos. O Estado em determinadas ações tem suas funções diminuidas, tendo em vista a própria lógica do ideário neoliberal que minimiza o Estado e retira direitos importantes para o desenvolvimento de muitas famílias.

Este retrocesso é notado na política social neoliberal que se volta para o corte dos gastos sociais, o que indica redução dos serviços à sociedade e prejudica as condições de vida da população, além de gerar privatização e a centralização dos gastos sociais públicos em programas seletivos contra a pobreza. As políticas de proteção, voltadas às familias na Amazônia, constituiram-se ao longo da história em construções teóricas, distantes da realidade regional, tão pouco se aproximando da diversidade de características locais.

Para responder à problemática apresentada neste artigo, discutiremos primeiramente as particularidades amazônicas, vulnerabilidade e vigilância socioassistencial. Esta discussão parte da compreensão de que as especificidades regionais não podem ser tratadas com um único modelo, a cultura influencia o modo de ser e viver em cada território. Contudo, a vigilância social é uma função importante da política de assistência social que permite o conhecimento das diversas formas de vulnerabilidades sociais da população e padrões de serviços do território.

Por fim, será debatido sobre as demandas e ofertas no âmbito do Suas em particular no município de Parintins no estado do Amazonas. A partir deste recorte da realidade foi possivel 
produzir informações a respeito desse espaço heterogêneo e diversificado e refletir que cada ambiente amazônico mostra suas especificidades.

\section{Particularidades amazônicas, vulnerabilidades e vigilância social}

Partimos da percepção de Teixeira (2013), ao argumentar que se torna necessário compreender a complexidade da região amazônica, na qual a proteção social necessita ser analisada, a partir da localidade, potencialidade e diversidade cultural, a fim de se adequar às necessidades das famílias através de suas particularidades.

O Brasil, por ser um país com uma vasta diversidade cultural, geográfica e social, não pode aceitar uma política pública projetada sob a ótica da singularidade, pois nas diferentes regiões brasileiras as dimensões geográficas, cultural e a sociedade em geral, apresentam-se de forma peculiar.

É de grande valia conservar os modos de vidas dos grupos que se encontram espalhados nas regiões do país. Contudo, para se formular uma política pública embasada na ótica territorial é necessário conhecer e diagnosticar as demandas do território.

Dentre as características marcantes que compõem as particularidades na região amazônica estão os povos de comunidades tradicionais e rurais que vivem nas áreas que apresentam grandes indices de vulnerabilidades e necessitam de políticas públicas que dialoguem com suas realidades.

A diversidade é um elemento chave na região, onde diversas comunidades tradicionais, como indígenas, quilombolas, caboclos, caiçaras, ciganos, ribeirinhos, pescadores, quebradeiras de coco babaçu, cipozeiros, dentre outros povos que se encontram espalhados nos estados brasileiros e distantes do centro urbano, possuem modos de vida particulares que devem ser respeitados.

O direito à proteção social é inerente a qualquer pessoa, independentemente da nacionalidade, raça, etnia, credo, gênero, idade e cultura. Todavia, os povos de comunidades tradicionais encontram dificuldades na garantia de seus direitos.

Segundo Matias (2011, p. 17-18),
O maior desafio posto para a assistência social, no atendimento aos povos e comunidades tradicionais é, assim, o reconhecimento e a concretização dos seus direitos sociais, por meio da proteção de seus direitos e memórias culturais, suas práticas comunitárias e sua identidade racial e étnica, bem como as habilidades e competências dos trabalhadores do SUAS para atender esta especificidade, uma vez que as ações dos serviços, programas e projetos devem ser adaptadas para o atendimento das comunidades tradicionais.

Os trabalhadores do Suas devem ser capacitados para o atendimento de valores, culturas e tradições de cada segmento, uma vez que as familias indígenas e quilombolas "seguem a mesma regra dos demais em relação às condicionalidades nas áreas de saúde, educação e assistência social dos beneficiários do Programa Bolsa Família" (MATIAS, 2011, p. 19).

O meio rural, como território de vida, também se evidencia como um dos mais propensos ao desenvolvimento de vulnerabilidades e riscos sociais, pois a população residente no campo, na maioria das vezes, não tem acesso aos serviços básicos como saúde, educação, habitação, saneamento básico, principalmente à assistência social, visto que as especificidades do rural pouco são consideradas no delineamento das políticas públicas.

As precariedades de infraestrutura na área rural, especialmente de energia elétrica e água encanada, privam as familias rurais de uma série de facilidades já acessiveis aos meios urbanos. Nos últimos anos, apesar do avanço das políticas públicas, são ainda insuficientes frente à grande demanda da população e desigualdades existentes (HEREDIA; CINTRAO, 2006).

Outra particularidade a destacar na Amazônia é a dependência de muitos municipios em relação às vias fluviais como meio de locomoção, são poucos os que contam com aeroporto e, quando há, os custos do transporte aéreo são exorbitantes.

De acordo com o Instituto Brasileiro de Geografia e Estatística (IBGE) (2016), as viagens de transporte público mais demoradas do país são feitas na Amazônia. Sendo uma tarefa árdua o complexo trajeto dentro da maior bacia hidrográfica do planeta. 
Os impactos dos regimes de cheia e seca dos rios, sobre as possibilidades de deslocamento é uma realidade que demanda diversos tipos de embarcações fluviais conforme rege as águas. 0 regime das águas é um elemento constante na vida amazônica, sobretudo dos ribeirinhos, mas impacta a região como um todo.

Segundo Teixeira (2013), a região amazônica coloca um desafio diferente ao principio da territorialidade. Sua particularidade regional pede especificidade na leitura da realidade social em seu território, e pede a introdução de ativos na potencialização da proteção social no âmbito do SUAS.

No âmbito da fauna e flora amazônica também ocorre uma dispersão da população, há comunidades que se distanciam uma da outra, municipios separados por horas ou dias de viagens dificultando o acesso às políticas públicas.

A prestação de serviços socioassistenciais nas áreas rurais e ribeirinhas da região amazônica possui custos mais elevados que em outras regiões do país, por isso, nessas localidades a provisão de cuidados e atenções de assistência social ainda são insuficientes ou muitas vezes inexistentes.

A Norma Operacional Básica do Sistema Único de Assistência Social (BRASIL, 2012) estabelece que a organização do Suas deve respeitar as diversidades culturais, étnicas, religiosas, socioeconômicas, políticas e territoriais, e reconhece que há especificidades e desigualdades regionais a serem consideradas no processo de planejamento e execução das ações. E, ao estabelecer a territorialidade como diretriz estruturante do Suas, aponta que o planejamento da oferta dos serviços socioassistenciais deve levar em conta as vulnerabilidades e riscos que impactam os territórios de forma diferenciada.

Diante das particularidades territoriais propõem-se olhar, pensar, pesquisar e refletir sobre a Amazônia, debater seu futuro, possibilitar o diálogo e investir em diversas condições de acesso que contribuirão para um melhor desenvolvimento, e assim, enfrentar os dilemas e desafios que se lançam sobre a região frente à crise do mundo globalizado.
Na realidade amazônica precisamos avançar bastante nas discussões sobre suas particularidades e complexidades para a efetivação dos serviços socioassistenciais. A política de assistência social precisa ser adaptada às questões regionais, uma vez que, para além das demandas setoriais e segmentadas, o chão onde se encontram e se movimentam setores e segmentos, faz diferença no manejo da própria política, significando considerar as desigualdades socioterritoriais na sua configuração (BRASIL, 2004). Esse é um destaque importante a ser considerado na implementação das políticas públicas nas regiões.

Segundo Scherer e Oliveira (2006), a Amazônia ainda vive inúmeras contradições evidenciadas em planos de governo desenraizados da história e dos lugares, do espaço e do tempo, onde ao mesmo tempo pode-se notar o acesso às avançadas tecnologias da modernidade e a falta de acesso da grande maioria da população às necessidades sociais básicas.

Os projetos de modernização da Amazônia brasileira não levaram em consideração a voz do homem amazônico, o qual ficou abandonado à beira das estradas, às margens dos rios e das florestas, longe das políticas públicas e sempre na esperança de melhores condições de vida, na perspectiva que tais projetos valorizem o ser que vive na Amazônia e não o identifique apenas como inferior ou primitivo, ainda que sua história seja marcada pela desigualdade.

Para Fialho Nascimento (2011), os projetos de desenvolvimento implantados na Amazônia, que resultam em volumes de bens e serviços produzidos na região, expresso pelo crescimento do PIB nos últimos anos, não têm significado um desenvolvimento social para a sua população.

Em relação aos dados de 2010, o IPEA (2015) aponta que na região Norte, 41,9\% dos municípios encontram-se no grupo de Índice de Vulnerabilidade Social (IVS) muito alto. O estado que apresenta maior percentual de municipios nessa faixa do IVS é o Amazonas, com $80,6 \%$, seguido do Pará, com 63,6\%.

As análises de Scherer (2009) sobre a vulnerabilidade na Amazônia contribuem para que possa- 
mos refletir sobre as especificidades dessa região tão complexa e cheia de desafios e paradoxos, sendo um espaço natural imerso de riquezas e ao mesmo tempo é considerada a segunda região do país onde se localizam os municipios com Índices de Desenvolvimento Humano (IDH) mais baixos, conforme os dados apresentados a seguir:

No estado do Pará, dos 143 municípios existentes, 25 têm os menores indices de desenvolvimento humano, logo seguido pelo estado do Amazonas, com os 62 municipios, entre os quais Envira, Ipixuna, Tapauá no alto Solimões, com índices baixos de desenvolvimento humano. Nessa região concentra o maior indice de hanseniase. Em cada dez mil habitantes, a média dos dados registrados é de 6,6, conforme dados da Secretaria Municipal de Saúde. Em 2005, foram registrados 38.410 casos de hanseniase, dados que revelam presença viva e ativa de estruturas sociais do passado (SCHERER, 2009, p. 9).

Diante desses dados, verifica-se a importância da política de assistência social para a Amazônia brasileira e os desafios a serem enfrentados por ela frente aos componentes regionais, fazendo-se necessária a vigilância socioassistencial.

Porém, em grande parte dos municípios ainda não houve a implementação da vigilância, pois há a necessidade de incorporação de "novas tecnologias aos trabalhos da assistência social, formando um banco de dados sobre a Questão Social na Amazônia, organizando o acervo de informações" (TEIXEIRA, 1997, p. 112). A vigilância socioassistencial necessita de um banco de dados da realidade local para uma melhor leitura das demandas e ofertas no campo desta política pública.

$O$ artigo $2^{\circ}$ da LOAS (LEI n. ${ }^{\circ} 12.435$, de 2011) afirma que a vigilância socioassistencial visa analisar territorialmente a capacidade protetiva das familias e nela a ocorrência de vulnerabilidades, de ameaças, de vitimizações e danos. O campo de atuação da vigilância opera tanto na produção de conhecimento sobre vulnerabilidades e riscos, como sobre os padrões de serviços, contribuindo para a efetivação das ações no âmbito da política de assistência social, devendo ser constituída nos municipios, estados e Distrito Federal.

A vigilância compreende que as situações de riscos e vulnerabilidades não se apresentam de forma igual, há graus e particularidades que requerem diferentes ações das políticas, em especial à política de assistência social.

No caso da Amazônia, gestores, conselheiros e trabalhadores do Suas, precisam "particularizar os serviços e beneficios socioassistenciais no que toca aos direitos dos povos da Amazônia e mais especificamente dos grupos étnicos (direitos indigenas, quilombolas e direitos ambientais)" (TEIXEIRA, 2013, p. 196).

Teixeira, também chama atenção para que não se individualize pessoas, em detrimento do grupo ou da etnia. "Ser indígena ou quilombola não é um atributo que funciona como agravante da condição de 'pobre'. Não confundir o ser 'típico' com o ser pobre" (2013, p. 196).

Portanto, a vigilância só se concretizará nos municipios se for apreendida a partir de uma nova cultura, a cultura da informação, que possibilitará uma nova forma de atuação, de enxergar a realidade e propor novas formas de ações nesse território. As necessidades e demandas da população precisam contar com políticas públicas que saibam ler e reconhecer as suas necessidades e valorize as suas demandas. Para tanto, o homem amazônico requer oferta de serviços compativeis à sua realidade local e que respeite a sua cultura e as diferenças sociais.

A vida amazônica participa ativamente dos benefícios e maleficios gerados pelo mundo globalizado. A globalização da esfera econômica originou uma nova configuração no contexto social, econômico e político nos estados da região impactando diretamente nas condições de vida da população local, principalmente das familias pobres vulneráveis.

\section{Demandas e ofertas no âmbito do SUAS amazônico}

Os riscos e vulnerabilidades geram necessidades de proteção, as quais por sua vez, o poder público deve responder com políticas sociais, sendo fundamental que a relação 'demanda e oferta' se adeque ao perfil do território. Há a necessidade de conhecer as vulnerabilidades, riscos e demandas, para que seja possivel ofertar 
serviços essenciais que assegurem o acesso aos direitos de cidadania.

As demandas no campo da assistência social têm se tornado crescente desde 1990, pois a década foi marcada pela permanência da desigualdade e da pobreza, principalmente a desigualdade de rendimentos, que apesar das oscilações após o plano real permaneceu em patamares elevados no Brasil. Segundo dados da Comissão Econômica para a América Latina e o Caribe (CEPAL) (2004), em 1990, 48\% da população vivia abaixo da linha da pobreza.

A Organização Internacional do Trabalho (OIT) (2003, p. 2) considera que a pobreza é "resultado de falhas estruturais e de sistemas econômicos e sociais ineficazes. É o fruto de respostas políticas inadequadas, de políticas muito pouco imaginativas e de apoio internacional insuficiente".

A pobreza na Amazônia se situa em meio à abundância, não é uma pobreza de recursos naturais, nem graves problemas de falta de alimentos, mas de pouco ou nulo acesso às políticas públicas, de oportunidades, de possibilidades, de informações, de direitos inerentes à sobrevivência humana, de reconhecimento e respeito às etnias amazônicas e seus diferentes paradigmas socioculturais.

Considera-se que a pobreza pode ser agravada se a provisão dos serviços públicos for precária ou nula, impossibilitando a população, especialmente aos mais pobres ao acesso à rede de proteção social, aos serviços sociais e de infraestrutura. Sem acesso à rede de serviços públicos a tendência é que essa população pobre recaia em uma situação de vulnerabilidade e fique exposta aos riscos sociais (YAZBEK, 2008).

Em relação à vulnerabilidade aos direitos básicos, Kowarick discorre que os aparelhos públicos de proteção social "não só sempre foram restritos e precários como também, em anos recentes, houve desmonte de serviços e novas regulamentações legais que se traduziram da perda de direitos adquiridos" (2009, p. 68).

Essa fragilização de cidadania tem sido acompanhada pela desresponsabilização do Estado em relação aos direitos de cidadania, havendo um verdadeiro desmonte de direitos básicos frente ao ditame neoliberal. Esse cenário está bem presente em tempos atuais com as contrarreformas do governo brasileiro.

Diante desse contexto, as necessidades básicas se apresentam de forma mais evidente frente às vulnerabilidades e necessidades inerentes às expressões da questão social. O atendimento do básico é justamente a base para o ser humano se desenvolver social e fisicamente.

Pereira analisa que "o básico é direito inegociável e incondicional de todos, e quem não o tem por falhas do sistema socioeconômico terá que ser ressarcido desse déficit pelo próprio sistema" (2007, p. 35).

Caso não ocorra a satisfação das necessidades básicas, Doyal e Gough apud Pereira (2007, p. 67) falam de "sérios prejuizos", pois a não satisfação de uma preferência pode causar sofrimento e criar eventuais prejuizos materiais ou psicológicos.

Marx e Engels (2007, p. 33) refletem sobre as necessidades essenciais, quando colocam em questão as condições de existência humana ao afirmarem que:

\begin{abstract}
Os homens têm de estar em condições de viver para poder "fazer história". Mas, para viver, precisa-se, antes de tudo, de comida, bebida, moradia, vestimenta e algumas coisas mais. $O$ primeiro ato histórico é, pois, a produção dos meios para a satisfação dessas necessidades, a produção da própria vida material, e este é, sem dúvida, um ato histórico, uma condição fundamental de toda a história, que ainda hoje, assim como há milênios, tem de ser cumprida diariamente, a cada hora, simplesmente para manter os homens vivos.
\end{abstract}

Conforme os autores supracitados, para que o ser humano possa estar em condições de viver precisa da satisfação das suas necessidades básicas. Assim, na atualidade, na busca de satisfação dessas necessidades, quando não encontradas via mercado com a venda e compra da força de trabalho, o individuo busca como alternativa a via do Estado, a partir das políticas públicas sociais.

Yazbek (2003), nos leva a compreensão de que o sistema de proteção social brasileiro não dá conta da imensa fratura, entre direitos sociais e possibilidades de acesso às políticas sociais em geral. 
A autora elucida que o social se torna um campo de luta e de manifestações dos espoliados, e chama atenção para a "incorporação das demandas dos subalternos, que ainda conformam as políticas sociais, põe em questão até que ponto essas políticas são ou não funcionais ao interesse da população [...]" (YAZBEK, 2003, p. 21-22).

As famílias do município de Parintins ${ }^{2}$ usuárias do Centro de Referência da Assistência Social, beneficiárias do Programa Bolsa Familia, demandam ações da política de assistência social local, que vão além da transferência de renda. seguem as principais demandas:

a) acesso a cursos de qualificação profissional ou geração de renda;

b) oficina para um melhor manejo da agricultura familiar e escoamento da pequena produção até as feiras da área urbana;

c) encaminhamento para um melhor acesso à política de saúde;

d) acesso à expedição de documentação.

Diante do exposto, a oferta dos serviços pelas políticas públicas precisa conhecer as situações de vulnerabilidades e riscos presentes nos territórios e nas familias residentes e chegar, principalmente, aos que vivem sob a "invisibilidade", para que ocorra de fato o atendimento das demandas e o aprimoramento de potencialidades e autonomia.

A seguir, será realizada uma análise de cada demanda apontada pelas familias entrevistadas.

\subsection{Acesso a cursos de qualificação profissional ou geração de renda}

As entrevistas foram realizadas com as familias da área urbana e do meio rural, constatou-se que 90\% das familias da área urbana que frequentam o CRAS passaram a frequentar os serviços com a esperança de ser ofertado um curso de capacitação profissional ou geração de renda. Já quanto às famílias da área rural, 60\%, têm a preocupação em relação aos jovens que ficam ociosos, sem atividades, o que gera a expectativa de uma qualificação visando à empregabilidade e uma esperança da nova geração ter a oportunidade de exercer uma atividade para além do campo.

A esperança da empregabilidade é depositada pelos pais e avós dos jovens, que enxergam nestes uma possibilidade de crescer profissionalmente. A grande maioria dos jovens entrevistados que concluíram o ensino médio almejam a sua inserção ao mercado de trabalho para contribuir com as despesas da familia, em detrimento de seu ingresso na universidade. Pois ocorre a preocupação de não conseguir manter-se na universidade sem recursos. Assim, as familias enxergam na qualificação profissional de curto prazo uma oportunidade para inserção no mundo do trabalho.

No municipio de Parintins, no periodo de 2015 a 2017, a política de assistência social não viabilizou serviços de qualificação profissional ou geração de renda, apenas realizou oficinas com desenho e pintura e palestras nos Centros de Referência de Assistência Social (CRAS), sendo sentida a necessidade de oficinas com trabalhos manuais como a confecção de artesanatos, em que aprendam e possam produzir produtos para a venda.

Nota-se que a preparação para o trabalho e a inclusão produtiva é uma das maiores demandas dos usuários da assistência social, porém "a preparação para o trabalho e inclusão produtiva não compõem o rol de ações implementadas pelo PAIF" (BRASIL, 2012, p. 77). O PAIF é o Serviço de Proteção e Atendimento Integral à Familia, que exerce atividades de fortalecimento de vínculos, oficinas, acolhida, dentre outras ações com as familias no âmbito dos CRAS.

Os CRAS de Parintins não estão equipados para receber os usuários para o atendimento de qualificação profissional, como um curso de informática, nem geração de renda, com cursos de culinária, confeitaria, artesanatos para venda. Assim como não foi identificado nenhuma parceria com Serviço Nacional de Aprendizagem 
Comercial (Senac), Centro de Educação Tecnológica do Amazonas (Cetam), Serviço Nacional de Aprendizagem Industrial (Senai) e programas de universidades que são centros de treinamentos profissionais existentes no município.

É fundamental que o órgão gestor da assistência social busque o estabelecimento de articulações com programas e projetos de preparação para o trabalho e inclusão produtiva e que o Centro de Referência da Assistência Social identifique potenciais usuários e os encaminhe para estas iniciativas (BRASIL, 2012).

Segundo as orientações do Manual de Gestão do Programa Bolsa Familia (2013), quando as vulnerabilidades apresentadas não constituírem objeto de atendimento da assistência social, devem ser realizados encaminhamentos para outras políticas públicas.

Na política de assistência social são considerados serviços da proteção social básica, aqueles que potencializam as familias como unidade de referência, visando o fortalecimento dos vínculos através do protagonismo de seus membros e da oferta de um conjunto de serviços locais que visam à convivência, a socialização e o acolhimento em famílias, cujos vínculos familiares não foram rompidos e a integração ao mercado de trabalho (BRASIL, 2004).

É indiscutivel que a contribuição primordial das políticas públicas, para a inclusão produtiva e qualificação profissional, deva ser a oportunidade de acesso dos trabalhadores mais pobres às oportunidades produtivas localmente disponiveis.

\subsection{Oficina para um melhor manejo da agricultura familiar e escoamento da pequena produção até as feiras da área urbana}

A demanda relacionada à oficina de manejo e compostagem orgânica é específica da comunidade rural para a assistência social. Sabe-se que esta é uma demanda apresentada que não consegue ser respondida por ações no âmbito da assistência social, vai além de uma única política pública, requer uma intersetorialidade para o planejamento de ações que atendam às necessi-

dades e demandas das familias das comunidades rurais e ribeirinhas.

A vida rural e ribeirinha requer ações particulares que devem ser pensadas pela assistência social em parcerias com órgãos do próprio governo local.

Há grande diversificação nos modos de vida
e trabalho em comunidades rurais amazôni-
cas, dentre as atividades mais desenvolvidas
pelas populações rurais, podemos destacar a
agricultura, principalmente a de base familiar,
a pesca nos lagos, rios e igarapés, o extrati-
vismo com a coleta de produtos florestais, a
caça de animais silvestres e a pecuária, que
está cada vez mais presente na região (SILVA;
FRAXE, 2016, p. 93).

A agricultura familiar mantém muitas famílias na área rural, sendo essa a principal atividade econômica. A comercialização de seu produto é essencial para a reprodução do modo de vida, porém, enfrenta dificuldades no escoamento da produção por não possuir apoio do poder público.

Em Parintins, há uma feira dos produtores rurais locais, onde eles têm a possibilidade de realizar a venda de seus produtos. Mas, nem todos têm a oportunidade de escoar os seus produtos, assim, quem não consegue transportá-lo devido aos custos, vendem por um valor menor aos chamados "atravessadores"3.

Os sujeitos da pesquisa da comunidade alegam que as ações do CRAS chegaram até eles apenas uma única vez, e que os(as) assistentes sociais, geralmente, atendem de forma particular os que descumprem as medidas de condicionalidades do programa Bolsa Familia.

A logística necessária para a efetivação dos serviços na realidade amazônica requer um maior investimento, uma vez que a região em sua abrangência territorial é composta por vias fluviais, pela sua baixa densidade demográfica e pelo movimento das águas durante o período das enchentes e vazantes dos rios, tornando dificil o alcance às familias dispersas em uma vastidão territorial.

Compreender a prática profissional dos assistentes sociais na Amazônia requer apreender os desafios da proteção social neste território,

3 Comerciantes livres, que atuam na função de repassar o produto para outros compradores. 
assim como as oportunidades existentes que só se efetivarão com mais intensidade a partir da participação e protagonismo de seus agentes regionais e locais.

É de grande valia conservar os modos de vidas dos grupos que se encontram espalhados nas regiões do país. A proteção social ofertada na maioria das comunidades rurais no Brasil mostra-se ineficiente, na medida em que os serviços socioassistenciais desconhecem muitos individuos que, inclusive, fazem parte do território de abrangência do Centro de Referência da Assistência Social. Dessa forma, enormes contingentes dessa população são privados dos benefícios e não usufruem dos direitos garantidos na Constituição.

\subsection{Encaminhamento para um melhor acesso à política de saúde}

A saúde física é uma condição para que se possa viver, é um componente relevante do bem-estar, sem ela o ser humano estará impedido de muitas realizações. O atendimento à saúde é uma necessidade básica demandada pelas famílias da área urbana e com mais intensidade na área rural.

Apesar da dificuldade de acesso ao atendimento na área urbana, as famílias são privilegiadas por estarem próximas aos equipamentos públicos de atendimento, diferente dos que estão na área rural e ribeirinha que têm seu acesso dificultado também pelas longas distâncias.

Em Parintins a rede de saúde comporta dois hospitais, Unidades Básicas de Saúde, Policlinica, Centro de Atenção Psicossocial, Banco de Sangue, clínicas médicas particulares, que atendem ao SUS, laboratórios de exames, clínicas de diagnóstico por imagem e clínicas odontológicas. "Notou-se que a maioria desses serviços passou a ser oferecida na cidade após 2005 e que a demanda ainda não é suprida pelos mesmos" (SCHOR; OLIVEIRA, 2016, p. 50), nos casos mais graves a população local busca atendimento nas cidades de Manaus ou Belém.
As familias residentes da área rural alegam que quando há atendimento em algum posto de saúde localizado próximo à comunidade, este é realizado quase sempre por enfermeiros e que dificilmente encontram medicamentos. No caso de comunidades com ausência de algum posto de saúde, geralmente a população busca remédios caseiros com plantas consideradas medicinais.

Em regiões interioranas do Amazonas na "ausência médica adequada, é muito comum o uso de remédios caseiros para combater a doença. O que provavelmente não seja o suficiente para resolver determinadas enfermidades" (RANCIARO, 2004, p. 112).

A distância é um fator crítico no Amazonas, limita o acesso das pessoas aos principais centros de assistência à saúde, assim como se torna um grande desafio para a saúde pública o desenvolvimento da Atenção Primária à Saúde (APS), nas comunidades rurais à margem dos rios da Amazônia e em comunidades rurais de difícil acesso (SILVA; DALAMA; MORAIS et al., 2013).

Para Ranciaro (2004), de um ponto de vista mais amplo, as condições institucionais de saúde na Amazônia são ainda bastante precárias, tanto qualitativamente, como quantitativamente. Na impossibilidade da plena realização dos indivíduos, morre-se por falta de um soro, pela impossibilidade de um curativo, cujo material apropriado the salvaria a vida.

Para as familias entrevistadas a demanda para a assistência social é para que realize a mediação no acesso ao atendimento na área da saúde, principalmente das comunidades mais longínquas, fato que não tem ocorrido. Corrobora-se que parte significativa da população tem concebido à assistência social a tarefa de ser a política de proteção social, e não parte da política de proteção social (MOTA, 2008).

Portanto, as demandas apresentadas à assistência Social, quando for objeto de atendimento de outras políticas públicas, devem ser realizadas com encaminhamentos e acompanhamento dos usuários em situação de vulnerabilidade, haven- 
do, assim, uma interação com outras politicas e a possibilidade de maior eficácia de suas ações.

\subsection{Acesso à expedição de documentação}

A questão geográfica que é um componente bastante debatido quando se fala de Amazônia, também limita o acesso à cidadania de famílias que demandam por documentação, com dificuldades, sobretudo para obter a documentação básica, como a Certidão de Nascimento, o documento de Identidade (Registro Geral) e o Cadastro de Pessoa Física (CPF).

O acesso à documentação significa um alcance na vida de cada cidadão. Pois, a partir desta aquisição o idoso poderá acessar os benefícios previdenciários e assistenciais, as crianças e os jovens poderão estudar e serem atendidos na rede de saúde, assim como receber benefícios sociais.

Para que o cidadão da comunidade rural ou o ribeirinho se desloque para acessar essa documentação básica terá que custear despesas que vão além do que, muitas vezes, possui. Pois, a viagem pelos rios da Amazônia custa caro. Assim, diante das dificuldades, muitos brasileiros vão se tornando invisiveis.

Essa demanda relacionada ao acesso à documentação colocada pelas famílias da área rural, também não foi viabilizada pela assistência social municipal, nem encaminhada aos setores competentes do município, não exercendo a articulação com as demais políticas.

No estado do Amazonas, geralmente, ocorrem ações gratuitas de cidadania através de barcos do governo em determinadas localidades rurais, voltadas às demandas relacionadas à emissão de documentos, atendimento à saúde e Previdência Social. As embarcações coordenadas pela Secretaria de Estado de Justiça, Cidadania e Direitos Humanos (Sejusc) atendem especialmente às comunidades rurais e indigenas com dificil acesso às políticas públicas.

Contudo, os barcos da cidadania não conseguem atingir todas as calhas dos rios durante $o$ ano, mas é um tipo de ação particularizada que alcança uma parcela das demandas relacionadas à cidadania.
Diante dessas quatro demandas das familias da área urbana e rural apresentadas neste item, notou-se que não houve o atendimento de suas demandas a partir da oferta dos CRAS, nem mesmo o encaminhamento às outras políticas públicas para facilitar o acesso dos que estão em situação de vulnerabilidade, necessitando do apoio da proteção social básica.

Foi identificado que os CRAS de Parintins, durante o período de 2015 a 2017, ofertaram apenas oficinas de desenho artístico, pintura em tecido, dança e lazer para os idosos e crianças, além de palestras e visitas domiciliares. São ações paliativas, sem muito atrativo para os demais membros das familias.

Segundo as Orientações Técnicas do PAIF (2012), as oficinas em geral com as familias têm por intuito suscitar reflexões sobre um tema de interesse das familias, sobre vulnerabilidades e riscos, ou potencialidades, identificados no território, contribuindo para o alcance de aquisições, em especial, o fortalecimento dos laços comunitários, o acesso a direitos, o protagonismo, a participação social e a prevenção.

Fazer essas familias refletirem sobre sua situação de vulnerabilidade, riscos e potencialidades é de grande relevância, mas também devem ser dadas oportunidades de alternativas para o enfrentamento dessas vulnerabilidades com a garantia de direitos, fazendo com que essas familias neguem a condição de passividade e tenham condições de desenvolver seu protagonismo e autonomia.

Os CRAS do município de Parintins precisam avançar em ações adaptadas às particularidades locais. Um modelo de ação adaptada seria a instalação de CRAS itinerante fluvial, ou seja, embarcações que levem ações da assistência social às familias de áreas ribeirinhas.

As ações da área urbana também precisam de um olhar adaptado às vulnerabilidades locais, daí a importância da vigilância social para a elaboração e produção de diagnósticos. A partir deste, é possível capturar as necessidades das familias e a oferta dos serviços para que a população acesse aos serviços de proteção social 
adaptadas à realidade, possibilitando melhorias na qualidade de vida e nos indicadores de pobreza e vulnerabilidades.

Ao falar de ofertas adaptadas à realidade local, destaca-se o atendimento às famílias de quilombolas e indigenas, que na percepção de Matias (2011, p. 18):

Os técnicos de referência do CRAS devem realizar a busca ativa para o cadastramento de familias quilombolas e indigena no Cadúnico. Para o cadastramento de famílias indigenas deverá ser realizado um diagnóstico prévio, em parceria com a FUNAI, sobre as condições de vulnerabilidade social do povo indígena em questão.

No estado do Amazonas, há um total de 632 familias quilombolas, inscritas no Cadastro Único do Governo Federal e 465 famílias quilombolas beneficiárias do Programa Bolsa Família. Quanto aos indigenas há 43.533 familias cadastradas e 33.955 familias beneficiárias do Programa Bolsa Familia. Em relação às famílias ribeirinhas há 26.730 cadastradas e 20.659 beneficiárias do Programa Bolsa Familia. Quanto às familias que vivem em áreas rurais há um total de 73.148 famílias de agricultores e 54.766 beneficiárias do Programa Bolsa Familia (BRASIL, 2019).

Ressalta-se que as familias indigenas e quilombolas seguem a mesma regra dos demais em relação às condicionalidades nas áreas de saúde, educação e assistência social dos beneficiários do Programa Bolsa Familia (MATIAS, 2011, p. 19).

A assistência social ao fazer referência aos valores, culturas e tradições dos povos e comunidades tradicionais e ao contextualizar o urbano e rural, direciona o olhar para particularidades e especificidades dos vários Brasis. A partir deste olhar há a possibilidade de elaboração de uma proposta de capacitação aos trabalhadores do SUAS, para a qualificação da oferta dos serviços socioassistenciais aos indigenas e quilombolas, uma vez que estes seguem as mesmas regras de condicionalidades do Programa Bolsa Família.

Contudo, a pouca eficiência dos serviços ofertados pela proteção social básica, também se reflete pela baixa efetividade dos investimentos no social em vários municípios do país, inclusive em Parintins, tornando algumas ações inoperantes.

Yazbek (2003), em sua crítica sobre a política social brasileira, afirma que estas são políticas casuísticas, inoperantes, fragmentadas, superpostas, sem regras estáveis ou reconhecimento de direitos. Constituem-se de ações que, no limite, reproduzem a desigualdade social na sociedade brasileira.

Este tipo de tratamento dos poderes públicos às politicas sociais, em destaque à Política de Assistência Social, que dentre as politicas de seguridade social é a que possui o menor recurso, implica em reprodução da desigualdade social e manutenção na pobreza aos segmentos mais pauperizados. Os serviços de proteção social são ofertados de forma restrita e precárias aliados aos desmontes de direitos adquiridos, restando às familias em situação de vulnerabilidade, a resistência.

\section{Considerações finais}

A redução do orçamento do Sistema Único de Assistência Social (Suas) sinaliza um caminho para o desmonte desse sistema. Os serviços estão sendo reduzidos, os CRAS e CREAS estão precarizados e a oferta, em grande parte, não tem atendido às demandas dos usuários.

Historicamente, a assistência social é o campo onde os segmentos pauperizados e vulneráveis buscam um conjunto de ações que são de fundamental importância para essa população alvo. "A assistência é possibilidade de reconhecimento público da legitimidade das demandas dos subalternos e espaço de ampliação de seu protagonismo como sujeito" (YAZBEK, 2003, p. 55).

A falta da intersetorialidade por parte da Política de Assistência Social pôde ser notada nas narrativas dos sujeitos da pesquisa, quando afirmam que nenhum membro de sua família chegou a ser encaminhado ou teve facilitado a sua intermediação às outras políticas públicas. É imprescindivel que a assistência social busque articulação com outras políticas, programas e projetos para que, quando se deparar com situações que não são de sua competência, faça o devido encaminhamento.

As demandas apresentadas pelas familias entrevistadas não conseguem ser respondidas 
apenas por ações no âmbito da Assistência Social, vão além de uma única política pública, e as demandas que podem ser respondidas não estão sendo priorizadas frente à precarização dos serviços e dos recursos limitados, ou não são adaptadas à realidade local.

Observa-se que, em um cenário de crise pela qual passa o Brasil, tem ocorrido o aumento da demanda por assistência social e, de forma concomitante, as políticas sociais estão sendo retiradas ou inviabilizadas por falta de recursos. Esse retrocesso na área social levará muitas famílias à intensificação dos graus de vulnerabilidade social.

É importante para os CRAS a formação de redes e parcerias, onde se possa fortalecer a política de inclusão produtiva adaptada à realidade local. No municipio de Parintins há o Serviço Social do Comércio (Sesc), o Senac, Senai, as universidades como a Universidade Federal do Amazonas (UFAM), a Universidade do Estado do Amazonas (UEA), e o Instituto Federal de Educação Ciência e Tecnologia do Amazonas (IFAM), essas instituições podem se tornar facilitadoras para o processo de inclusão produtiva.

O fato de o CRAS não trabalhar com a inclusão produtiva, não o impede de facilitar o acesso das famílias às políticas e programas que têm o objetivo desta oferta. A política de assistência social deve firmar parcerias com as outras políticas e instituições de ensino e pesquisa, que podem contribuir com um diferencial no processo de desenvolvimento de ações de inclusão produtiva.

As políticas públicas contribuem para uma sociedade mais justa, contudo, a luta tem que ser constante para manter as conquistas, é preciso resistir. Torna-se de grande importância pensar em planejamentos de políticas públicas capazes de atender às realidades distintas, observar as vulnerabilidades locais, a complexidade da vida econômica e social, para que assim possa haver um melhor aproveitamento de suas potencialidades.

A análise da adequação entre as demandas da população e as ofertas dos serviços e benefícios socioassistenciais, vistos na perspectiva do ter- ritório, deve constituir-se como objeto central e de permanente reflexão de gestores no âmbito do SUAS, para que assim, se pense na Amazônia a partir daqueles que nela vivem.

\section{Referências}

BRASIL. Lei Orgânica da Assistência Social (LOAS), $n^{\circ}$ 8.742 de 7 de dezembro de 1993. Dispõe sobre a organização da Assistência Social e dá outras providências. DOU: seção 1, Brasilia, DF, p. 18769, 8 dez. 1993.

BRASIL. Norma Operacional Básica da Assistência Social- NOB. Resolução n 33 , de 12 de dezembro de 2012. Aprova a Norma Operacional Básica do Sistema Único de Assistência Social - NOB/SUAS. DOU: seção 1. Brasilia, DF, p. 155, 3 jan. 2013.

BRASIL. Política Nacional de Assistência Social. São Paulo: Editora Cortez, 2004. Versão oficial.

BRASIL. Trabalho Social com Familias do Serviço de Proteção e Atendimento Integral às famílias - PAIF. Brasilia: MDS, DF, 2012.

BRASIL. Relatório de Informações Sociais. Brasilia, DF: Ministério da Cidadania, 2019. Disponivel em: http:// mds.gov.br/bolsafamilia. Acesso em: 10 dez. 2019

COMISSÃO ECONÔMICA PARA A AMÉRICA LATINA. Panorama Social da América Latina 2001-2003: sintese. [S. I.]: Publicação das Nações Unidas, mar. 2004. ISBN 9213223021.

COSTA, Marco Aurélio; MARGUTI, Bárbara Oliveira (ed.) Atlas da vulnerabilidade social nas regiões metropolitanas brasileiras. Brasilia: IPEA, 2015.

FIALHO NASCIMENTO. Questão Social, Desenvolvimento Capitalista e Desigualdade Social na Amazônia. In: JORNADA INTERNACIONAL DE POLITICAS PÚBLICAS, 5., 2011, São Luiz. Anais [...]. São Luiz: UFMA, 2011.

HERÉDIA, Beatriz Maria Alásia; CINTRÃO, Rosangela Pezza. Gênero e acesso a políticas públicas no meio rural brasileiro. Revista Nera, Presidente Prudente, SP, ano 9, n. 8, p. 1-28, jan./jun. 2006.

INSTITUTO BRASILEIRO DE GEOGRAFIA E ESTATISTICA. Mapeamento das conexões rodoviárias e hidroviárias brasileira, 2016. Rio de Janeiro, 2017. Disponivel em: https://www.ibge.gov.br/geociencias/organizacao-do-territorio/redes-e-fluxos-geograficos/15794-rodoviarias-e-hidroviarias.html?=\&t=sobre. Acesso em: 12 dez. 2019

KOWARICK, Lúcio. Viver em risco: sobre a vulnerabilidade socioeconômica civil. São Paulo: Ed. 34, 2009.

MARX, Karl. A ideologia alemã: crítica da mais recente alemã em seus representantes Feuerbach, B. Bauer e Stiner, e do socialismo alemão em seus diferentes profetas. Tradução de Rubens Enderle, Nélio Schneider e Luciano Cavini Martorano. São Paulo: Boitempo, 2007. 
MATIAS, Mariana López. Documento técnico contendo a estruturação e proposta de uma matriz de conteúdos comuns a todos os niveis de proteção social (básica, especial e gestão), organizados de acordo com o perfil do público (formação, função, nivel de proteção social que atua), especificidades regional/local, contexto urbano e rural, presença de povos e comunidades tradicionais. Produto 02, Brasília: IPEA, 2011.

MOTTA, Ana Elizabete. A centralidade da Assistência Social na seguridade social brasileira dos anos 2000. In: MOTTA, Ana Elizabete (org.). O mito da Assistência Social, ensaios sobre estado polícias e sociedade. 2. ed. ver. e ampl. São Paulo: Cortez, 2008. p. 133-146.

ORGANIZAÇÃO INTERNACIONAL DO TRABALHO. Relatório Global: Discriminação no Trabalho: A Hora para Igualdade no Trabalho. Relatório Global 2003. Genebra: OIT, 2003. Suplemento Nacional.

PEREIRA, Potyara A.P. Necessidades Humanas: subsídios à crítica dos mínimos sociais. 4. ed. São Paulo: Cortez, 2007.

RANCIARO, Maria Magela Mafra de Andrade. Andirá: memórias do cotidiano e representações sociais. Manaus: EDUA, 2004

SCHERER, Elenise. Vulnerabilidade Social na cidade de Manaus: o avesso do progresso. In: SCHERER, Elenise (org.). Questão Social na Amazônia. Manaus: EDUA, 2009. p. 129-163.

SCHERER, Elenise; Oliveira, José Aldemir (org.). Amazônia: políticas públicas e diversidade cultural. Rio de Janeiro: Garamond, 2006. p. 9-15

SCHOR, Tatiana; OLIVEIRA, José Aldemir. Parintins: a geografia da saúde na formação da cidade média de responsabilidade Territorial no Amazonas. In: BARTOLI, Estevan et al. Parintins: Sociedade, Territórios \& Linguagem. Manaus: EDUA, 2016. p. 35-58.

SILVA, Charlene; FRAXE, Therezinha. Trabalho, cultura e modos de vida em áreas rurais amazônicas: um olhar critico sobre a agricultura e a pesca no Zé Açu, municipio de Parintins/Am. In: BARTOLI, Estevan et al. Parintins: Sociedade, Territórios \& Linguagem. Manaus: EDUA, 2016. p. 93-115.

SILVA, Patricia; DALAMA, Luiz; MORAES, Maria, Organização do cuidado à saúde em populações ribeirinhas: experiência de uma unidade básica de saúde fluvial. In: CONGRESSO BRASILEIRO DE POLITICA, PLANEJAMENTO E GESTÃO EM SAÚDE. 2., 2013, Belo Horizonte. Anais [...]. Rio de Janeiro: Abrasco, 2013. p. 1-12.

TEIXEIRA, Joaquina Barata. A Amazônia e a interface com o SUAS. In: CRUS, José Ferreira et al. (org.). Coletânea de Artigos Comemorativos dos vinte anos da Lei Orgânica da Assistência Social. 1. ed. Brasília: Ministério de Desenvolvimento Social e Combate à Fome, 2013. p. 188-203. Disponivel em: https://www.mds. gov.br/webarquivos/publicacao/assistencia_social/ Livros/20anosLOAS.pdf. Acesso em: 13 out. 2017.

TEIXEIRA, Joaquina Barata. A assistência social na Amazônia. Serviço Social e Sociedade, São Paulo, v. 19, n. 56, p. 97-113, mar. 1998.
YAZBEK, Maria Carmelita. Estado, Políticas Sociais e implementação do SUAS. In: BRASIL, CapacitaSUAS. SUAS: configurando os eixos de mudança. 1. ed. Brasília: Ministério do Desenvolvimento Social e Combate à Fome, Instituto de Estudos Especiais da Pontificia Universidade Católica de São Paulo. 2008. v. 1, p. 79-125.

YAZBEK, Maria Carmelita. Classes subalternas e assistência social. 4.ed. São Paulo: Cortez, 2003.

\section{Dayana Cury Rolim}

Doutora em Sociedade e Cultura na Amazônia (UFAM), em Manaus, AM, Brasil; professora adjunta da Universidade Federal do Amazonas, Instituto de Ciências Sociais, Educação e Zootecnia (ICSEZ), em Parintins, Amazonas, Brasil. Integrante do Grupo de Estudo e Pesquisa em Politicas Sociais e Seguridade Social no Amazonas.

\section{Endereço para correspondência}

Dayana Cury Rolim

Universidade Federal do Amazonas

Estrada Parintins Macurany, 1805

Jacareacanga, 69152-240

Parintins, AM, Brasil

Os textos deste artigo foram revisados pela Poá Comunicação e submetidos para validação da autora antes da publicação. 